\title{
Regulation of Pancreatic Lipase by Dietary Medium Chain Triglycerides in the Weanling Rat
}

\author{
RUTH Z. BIRK AND PATSY M. BRANNON \\ The Institute of Applied Biosciences, Department of Biotechnology Engineering [R.Z.B], Ben-Gurior \\ University, Beer-Sheva, 84105, Israel; and Department of Nutrition and Food Science [P.M.B.], \\ University of Maryland, College Park, Maryland 20742, U.S.A.
}

\begin{abstract}
Pancreatic lipase (PL) and its related protein 1 (PLRP1) are regulated by the amount of dietary fat through an apparent transcriptional mechanism. Regulation of PL and PLRP1 by type of fat (chain length and degree of saturation) is less well understood. The aim of this study was to determine whether mediumchain triglycerides regulate PL and PLRP1. For $7 \mathrm{~d}$, weanling (21-d-old) Sprague Dawley male rats were fed diets low (11\% of energy), moderate $(40 \%$ of energy), or high ( $67 \%$ of energy) in trioctanoate/tridecanoate (MCT) or safflower (low fat only) oils. Food consumption decreased as dietary MCT increased, and the consumption of MCT diets was lower than that of the lowsafflower (control) diet. Final body weight was similar among rats fed the low- or moderate-MCT or control diets, but was significantly reduced $(17 \%)$ in those fed the high-MCT diets. PL activity was significantly elevated $53-60 \%(p<0.002)$ in rats fed low and moderate MCT diets, respectively, compared with
\end{abstract}

that of rats fed high-MCT or control diets. PL and PLRP1 mRNA levels were not significantly different among diets, suggesting that chain length regulates PL and PLRP1 translationally or posttranslationally. The $\beta$-hydroxybutyrate plasma concentration was significantly $(p<0.02)$ higher $(85 \%)$ in rats consuming low-MCT diet compared with those of rats fed the control diet. MCT at low levels, but not high levels, increase PL activity without changing its mRNA levels. (Pediatr Res 55: 921-926, 2004)
Abbreviations
MCT, medium-chain triglycerides
PL, pancreatic lipase
PLRP1, pancreatic lipase related protein 1
PLRP2, pancreatic lipase related protein 2
LCT, long-chain triglycerides

Pancreatic lipase (PL) is the main enzyme responsible for digestion of dietary triglycerides. PL catalyzes the hydrolysis of $56 \%$ of the fatty acids of dietary triglycerides, and gastric lipase, an additional $10 \%$ (1). PL and its related protein PLRP1, a homologous protein of unknown function (2), are secreted by the pancreas and regulated by dietary fat (3-5). Considerable amount of work has been reported about the dietary regulation of PL by triglycerides, but many of the studies before 1994 used a cDNA probe initially believed to be PL and subsequently shown to be PLRP1 (2). PL was initially cloned by Lowe and co-workers (6) and referred to as rat PL3 by Wicker-Planquart and Puigserver (7). PL demonstrates the classical dependence on colipase for its lipolytic activity. PLRP1 (known before 1994 as pancreatic lipase 1/2) is highly homologous to PL $(65 \%)(2,8)$, but to date no known lipolytic

Received June 19, 2003; accepted February 16, 2004.

Correspondence: Ruth Birk, Ph.D., The Institute of Applied Biosciences, Department of Biotechnology Engineering, Ben-Gurion University, P.O. Box 653, Beer-Sheva 84105, Israel; e-mail: rbirk@bgumail.bgu.ac.il

Supported by Maryland Agricultural Experiment Station 97-72 grants "Developmental and Dietary Regulation of Pancreatic Lipase." Trioctanoate/tridecanoate (Neobee 1053) was a gift of the Stepan Company, Maywood, NJ, U.S.A.

DOI: 10.1203/01.PDR.0000127430.04127.4F activity of PLRP1 has been reported. Site-directed mutagenesis of two amino acids in PLRP1 to those seen in PL restores full colipase-dependent lipolytic activity of PLRP1, suggesting that PLRP1 may be a nonfunctional homologue of PL (9). Another homologue, pancreatic lipase related protein 2 (PLRP2) has $65 \%$ identity to PL and hydrolyzes triglycerides, phospholipids, and galactolipids. PLRP2 has low colipase dependence and does not exhibit bile salt inhibition as PL does $(2,8,10,11)$. It is unknown whether PLRP2 is regulated by dietary fat.

The pancreas normally produces and secretes 3 - to 10 -fold excess lipase; therefore, the physiologic importance of regulating PL has been questioned. However, the dietary regulation of PL mediates the response of cholecystokinin (CCK) to dietary fat by increasing the efficiency of triacylglyceride digestion in the proximal small intestine (12). The enhanced release of fatty acids in the proximal intestine increases the responsiveness of CCK and causes a "feed forward" effect that coordinates the digestion of dietary triglycerides (12). Similarly, humans who consume a fat meal with orlistat (a lipase inhibitor) have accelerated gastric emptying and reduced CCK release and output of lipase, trypsin, and bilirubin (13). Thus, PL plays an important role in the regulation of gastric emptying 
and pancreatic and biliary secretion after ingestion of fat in humans.

The amount of fat in the diet regulates PL and PLRP1 expression $(3,14-16)$. When a high-fat diet is introduced to rats, PL protein synthesis and content and PLRP1 mRNA levels increase within $24 \mathrm{~h}(36 \%, 20 \%$, and $412 \%$, respectively) (14). After $5 \mathrm{~d}$, PL content and synthesis and PLRP1 mRNA levels reach steady-state maximal levels (191\%, 217\%, and $650 \%$, respectively) (14). The regulation of PLRP1 by the amount of dietary fat is transcriptional, as demonstrated by increased nuclear transcript run-on assay (15). The parallel changes in PL mRNA levels (16) and synthetic rates (14) suggest that the regulation of PL is pretranslational and likely to be transcriptional. However, such transcriptional regulation has yet to be conclusively documented.

The regulation of PL and PLRP1 by the type of fat (chain length and degree of saturation) is controversial. DeschodtLanckman and co-workers (17) report a higher increase in PL activity by diets high in unsaturated triglycerides compared with those high in MCT (tricaprylin). Saraux et al. (18) report that MCT (C:8-C:10) do not increase PL activity and total content compared with longer chain triglycerides. Sabb and co-workers (19) report that PL activity is regulated similarly by different types of fat above a threshold of $49 \%$ of energy. Below that threshold level, only the highly unsaturated safflower oil and coconut oil, which is rich in MCT, stimulate PL activity. Ricketts and Brannon (16) report that the amount of fat, independent of its degree of saturation, regulates PL pretranslationally, as increasing either saturated or polyunsaturated dietary fat results in parallel changes in PL and PLRP1 mRNA levels. However, the degree of saturation of dietary fat regulates PL at other levels as well. Translational or posttranslational regulation is suggested because the increase in PL mRNA in rats fed the moderate lard diet does not result in a greater PL activity. Thus, the regulation of PL and its related proteins by dietary fat has multiple mechanisms. Further, the amount of fat regulates PL independently from the degree of saturation of the fat.

The effects of chain length, particularly in the range of $8-10$ carbon chain, on PL regulation remain controversial. MCT are used in some premature and newborn formulas because of their reported faster digestion and absorption (20-22). MCT are also used as a source of fat in processed foods and in nutrition therapy in medical conditions such as pancreatic insufficiency, malabsorption, parenteral nutrition, and weight loss (20-22). The mechanisms whereby MCT regulate PL and PLRP1 are unknown. The aim of this study was to investigate the regulation of PL mRNA and content by different amounts of dietary $\mathrm{MCT}$ in weanling rats.

\section{MATERIALS AND METHODS}

Experimental protocol. Twenty male weanling Sprague Dawley rats (Charles River Laboratories, Wilmington, MA) were housed individually in hanging cages in a temperaturecontrolled $\left(24^{\circ} \mathrm{C}\right)$ environment with a 12:12-h light-dark cycle. Weanling rats were selected as a model of normal fat digestion in the postnatal period. The protocol was approved by the
University of Maryland Animal Care and Use Committee, and the National Research Council's Guide for Care and Use of Laboratory Animals was followed. Rats were weight matched into four groups ( $n=5$ per group) so that the average initial weight was comparable: 46.8, 47.0, 46.6, 47.2 (g) for low-, moderate-, and high-MCT and low-safflower diet, respectively. The rats were fed for $7 \mathrm{~d}$ ad libitum purified low- (LF; $11 \%$ of energy), moderate- (MF; $40 \%$ of energy) and high- (HF; 67\% of energy) fat diets with MCT (trioctanoate/tridecanoate, Neobee 1053, Stepan, Maywood, NJ) or low-fat (11\% of energy) diet with safflower oil (control). The period of $7 \mathrm{~d}$ was selected because maximal adaptation and new steady-state levels are seen in PL content, synthesis, and mRNA levels after $5 \mathrm{~d}$ (14). The composition of the diets is shown in Table 1. These diets were isonitrogenous (either by percentage of weight or percentage of energy) and isoenergetic, but varied in content of cellulose, which has been shown not to affect the exocrine pancreas (23). Food consumption was measured daily, and body weights were measured on the first and last day of the experiment. On $\mathrm{d} 7$, the rats were euthanized by $\mathrm{CO}_{2}$ inhalation. Blood was drawn and frozen at $-80^{\circ} \mathrm{C}$ for $\beta$-hydroxybutyrate analysis. Pancreata were removed, and a portion was frozen immediately on dry ice and stored at $-80^{\circ} \mathrm{C}$ for enzyme analysis. The remainder of the pancreas was used immediately for RNA isolation as described below.

Pancreatic enzyme analysis. Pancreatic fragments were homogenized in nine volumes of PBS (PBS; $0.15 \mathrm{M} \mathrm{NaCl}, 5 \mathrm{Mm}$ $\mathrm{PO}_{4}, \mathrm{pH}$ 7.4) with a Polytron homogenizer (Brinkmann Instruments, Westbury, NY, U.S.A.). Homogenates were centrifuged at $14,000 \mathrm{~g}$ at $4{ }^{\circ} \mathrm{C}$ for $30 \mathrm{~min}$. The supernatant was removed and soybean trypsin inhibitor was added (final concentration $0.01 \%$ ). Lipase activity of the supernatant was assayed by a titrimetric method (19) with $20 \mathrm{mM} \mathrm{NaOH}$ using a gum arabic-stabilized emulsion of neutralized triolein with excess crude colipase. Lipase activity was expressed as units (micromoles FA released) per milligrams protein. Protein content of the supernatant was determined by the method of Lowry et al. (24), using bovine albumin as a standard.

Table 1. Dietary composition*

\begin{tabular}{lccc}
\hline & \multicolumn{3}{c}{ Diet } \\
\cline { 2 - 4 } & Low fat & Moderate fat & High fat \\
\hline Fat (\% energy) & 11 & 40 & 67 \\
Carbohydrate (\% energy) & 67 & 39 & 11 \\
Protein (\% energy) & 21 & 21 & 21 \\
Component & \multicolumn{2}{c}{ Percentage of diet (by weight) } \\
Casein & 20 & 20 & 20 \\
DL-methionine & 0.3 & 0.3 & 0.3 \\
AIN-76 mineral mix & 3.5 & 3.5 & 3.5 \\
AIN-93 vitamin mix & 1 & 1 & 1 \\
Choline bitartrate & 0.2 & 0.2 & \\
Cellulose & 5 & 19.2 & 32 \\
Fat $\dagger$ & 5 & 18 & 31.6 \\
Cornstarch & 65 & 37.8 & 11.3 \\
\hline
\end{tabular}

* Sabb et al. (19).

$\dagger$ Low-fat diet was either safflower oil or triotanoate/tridecanote oil. Moderate- and high-fat diets were triotanoate/tridecanote oil. 
及-hydroxybutyrate plasma levels. $\beta$-hydroxybutyrate levels were measured using Sigma Chemical kit 310-A (Sigma Chemical Co., St. Louis, MO, U.S.A.) (25).

RNA extraction and hybridization studies. RNA was isolated as described by Chomczynski and Sacchi (26). This method is a single extraction with an acid guanidinium thiocyanate-phenol-chloroform mixture. Freshly isolated pancreatic fragments were immediately homogenized with a Polytron homogenizer (titanium probe) for $2 \times 20 \mathrm{~s}$ in ice-cold $4 \mathrm{M}$ guanidinium thiocyanate, $26 \mathrm{mM}$ sodium citrate, $\mathrm{pH} 7,0.5 \%$ sarcosyl, and $0.7 \%$ 2-mercaptoethanol. Sequentially, the RNA was extracted by adding $0.2 \mathrm{M}$ sodium acetate $(\mathrm{pH} 4)$ and phenol and chloroform-isoamyl alcohol mixture (49:1). RNA was precipitated with isopropanol, reprecipitated with $75 \%$ ethanol, and dissolved in sterile diethyl pyrocarbonate (DEPC)-treated water. RNA was quantitated by UV absorption at $260 \mathrm{~nm}$. The integrity of RNA was checked by $0.8 \%$ agarose gel electrophoresis for the presence of intact $18 \mathrm{~S}$ and $28 \mathrm{~S}$ ribosomal RNA.

Recombinant plasmids used in these studies were the generous gifts of Dr. H.F. Kern, University of Marburg, Germany (PLRP1 cDNA; 0.82-Kb insert in Pst I site of pUC9) (27); Dr. J. Williams, University of Michigan (PL cDNA; $1.5-\mathrm{Kb}$ insert in EcoR I site of pUC18) (28); D. Soprano, Temple University, Philadelphia (28S cDNA probe); and Dr. P. Howells (PLRP2 cDNA; $1.3-\mathrm{Kb}$ insert in XdaI and KpNI site in pKSII) (29). Previously, we reported negligible cross-hybridization of LPL and PLRP1 (30). We also examined the specificity of the homologous and heterologous hybridization of random primelabeled PL, PLRP1, and PLRP2 cDNA inserts with $0.2 \mu \mathrm{g}$ of linearized plasmid DNA containing PLRP2 insert. Hybridization and washing conditions were identical to those described here. The PLRP2 cDNA cross-hybridization to PL and PLRP1 plasmid averaged 0 and $0.1 \%$, respectively, of its hybridization to the homologous PLRP2 plasmid. These results demonstrate the specificity of the hybridization of each PL probe under the highly stringent conditions used in this study. We have previously shown that rPL and PLRP1 do not cross-hybridize $(<3 \%)$ (29). Specific mRNAs were quantitated by dot-blot hybridization within the range of linear hybridization (30).

Total RNA was diluted in DEPC-treated water to the appropriate concentration verified by absorbance at $260 \mathrm{~nm}$. For denaturation, the samples were mixed with $6.15 \mathrm{M}$ formaldehyde in $0.75 \mathrm{M} \mathrm{NaCl}$ and $0.075 \mathrm{M}$ trisodium citrate $(5 \times \mathrm{SSC}$; $1 \times \mathrm{SSC}$ is $0.15 \mathrm{M} \mathrm{NaCl}$ and $0.015 \mathrm{M}$ sodium citrate, $\mathrm{pH} 7)$ and heated for $15 \mathrm{~min}$ at $65^{\circ} \mathrm{C}$. A within-filter control sample was spotted on each filter. The denatured samples were spotted onto a nitrocellulose filter using a Schleicher \& Schuell (Keene, NH, U.S.A.) dot-blot apparatus. The filters were cross-linked by UV radiation with optimal dosage $\left(120 \mathrm{~mJ} / \mathrm{cm}^{2}\right)$ and prehybridized at $42^{\circ} \mathrm{C}$ for $2 \mathrm{~h}$ in a solution containing $50 \%$ formamide $5 \times$ SSC, $5 \times$ Denhardt's solution, $0.1 \% \mathrm{SDS}$, and $100 \mathrm{mg}$ tRNA. Hybridization was performed at $42^{\circ} \mathrm{C}$ for $16-18 \mathrm{~h}$ after adding ${ }^{32} \mathrm{P}$-labeled cDNA probe. Plasmids containing cDNA inserts were labeled by nick translation for $28 \mathrm{~S}$ and by random priming for PL and PLRP-1 (Promega labeling kits Prime-aGene and Nick translation; Promega, Madison, WI, U.S.A.).
After hybridization, filters were washed under increasingly stringent conditions $(2 \times \mathrm{SSC}$ with $1 \% \mathrm{SDS}$ to $0.2 \times \mathrm{SSC}$ with $1 \%$ SDS). The films were autoradiographed overnight at $-80^{\circ} \mathrm{C}$. Autoradiographic films were quantitated by an area laser densitometer (Bio-Rad, Hercules, CA, U.S.A.) and volume integration. The data were expressed as relative absorbance units of each sample relative to the absorbance of $28 \mathrm{~S}$ RNA.

Data analysis. All data, expressed as mean $\pm \mathrm{SE}$, were analyzed by one-way ANOVA and least significant difference (LSD) (31). Results were considered significantly different if $p$ $<0.05$.

\section{RESULTS}

Food consumption and body weight. Food consumption was lower $(p<0.002)$ in rats fed HF-MCT diet (Table 2) compared with those fed LF-MCT (24\%) and MF-MCT (20\%) or LF-safflower (29\%) groups. Food consumption was comparable in the LF-safflower and LF-MCT groups and also in the LF-and MF-MCT groups. Body weight was comparable among the LF-safflower and MCT and the MF-MCT groups (Table 2), but was significantly reduced $(p<0.02)$ in the HF-MCT group compared with the rats fed LF-safflower, LF-MCT, and MF-MCT diets (13-17\%).

$\boldsymbol{P L}$ activity. PL activity (U/mg protein) was significantly elevated $(p<0.002)$ in rats fed LF- and MF-MCT diets compared with those fed LF-safflower diet $153 \%$ and $160 \%$, respectively). However, rats fed HF-MCT diet had comparable PL activity to those fed LF-safflower diet (Fig. 1). Pancreatic weights were not different among the experimental groups. Average pancreatic weights were: $0.42 \pm 0.05,0.39 \pm 0.04$, $0.42 \pm 0.03$, and $0.42 \pm 0.048$ (g) for LF-, MF-, and HF-MCT and LF-safflower-fed rats, respectively.

mRNA levels. PL mRNA levels were comparable in rats fed LF-safflower or LF-, MF-, and HF-MCT diets (Fig. 2). PLRP1 mRNA levels were also comparable between rats fed LFsafflower or LF-, MF-, and HF-MCT diets (Fig. 2). PLRP1 mRNA levels were lower than PL mRNA levels, as has been reported before (2) because of the anti-coordinate developmental pattern of PL and its related proteins in the rat. The mRNA levels of PLRP-1 and PLRP-2 are low throughout weaning and adulthood, whereas PL expression is high at weaning and adulthood (2). PLRP2 mRNA levels were not detectable in any of the total RNA samples from LF-safflower or LF-, MF-, and HF-MCT-fed rats (data not shown).

Table 2. Effect of MCT on food and total fat consumption and final body weight

\begin{tabular}{lccc}
\hline \multicolumn{1}{c}{ Diet } & $\begin{array}{c}\text { Food consumed } \\
(\mathrm{g} / \mathrm{d})\end{array}$ & $\begin{array}{c}\text { Total fat consumed } \\
(\mathrm{g} / \mathrm{d})\end{array}$ & $\begin{array}{c}\text { Final body weight } \\
(\mathrm{g})\end{array}$ \\
\hline LF safflower & $12.1 \pm 0.7^{*}$ & 0.6 & $94.6 \pm 9.6^{*}$ \\
LF-MCT & $11.3 \pm 1.2^{* \dagger}$ & 0.6 & $94.6 \pm 5.9^{*}$ \\
MF-MCT & $10.8 \pm 1.0 \dagger$ & 2.0 & $90.0 \pm 9.4^{*}$ \\
HF-MCT & $8.0 \pm 0.6 \ddagger$ & 2.7 & $78.4 \pm 5.6 \$$ \\
\hline
\end{tabular}

$* \dagger+$ Values (mean $\pm \mathrm{SE} ; n=5$ per group) for a given parameter not sharing a superscript differ significantly by ANOVA and LSD. There was a significant difference $(p<0.002)$ for food consumption. There was a significant difference $(p<0.02)$ for body weight. 


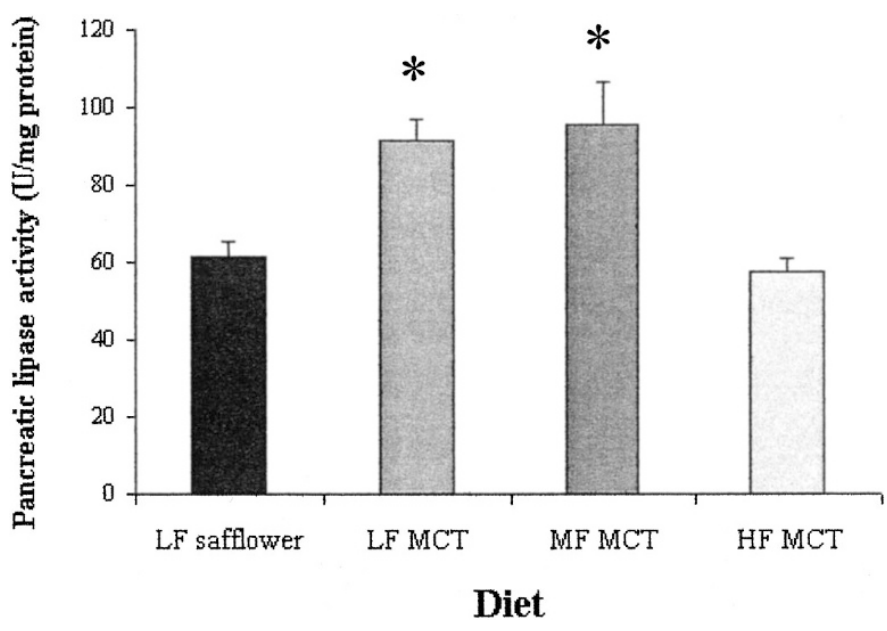

Figure 1. Effect of MCT on PL activity (U/mg protein). Weanling Sprague Dawley rats were fed for $7 \mathrm{~d}$ diets with LF- (11\% of energy), MF- ( $40 \%$ of energy), or HF-MCT (67\% of energy) or low-fat safflower (control) diets. Results are expressed as mean \pm SE $(n=5$ per group). *Values with superscript differed significantly from values without superscript $(p<0.002)$ by ANOVA and LSD.

及-hydroxybutyrate plasma levels. The $\beta$-hydroxybutyrate plasma concentration $(\mathrm{mg} / \mathrm{dL})$ was significantly higher $(85 \%, p$ $<0.02)$ in LF-MCT-fed rats compared with those in rats fed LF-safflower or HF-MCT. The $\beta$-hydroxybutyrate plasma concentration in rats fed MF-MCT was intermediate between its concentration in rats fed LF-MCT and LF-safflower (Fig. 3).

\section{DISCUSSION}

In this study, we describe significantly lower food consumption and final body weight in the rats consuming HF-MCT diet compared with those consuming LF- or MF-MCT and LFsafflower diets. Sabb et al. (19) found the same trend of decreased food consumption in rats consuming high-fat diets regardless of fat type. This trend in lower body weights (expressed as grams of weight gain per $100 \mathrm{Kcal}$ intake per day) with high MCT was noted in premature babies fed formula containing $40 \%$ of the fat in the diet as MCT, who had higher weight gain than those fed formula containing $80 \%$ of the fat in the diet as MCT (32). Elevated levels of MCT in the diet are proposed to alter body composition, resulting in more lean tissue and less fat. Epididymal fat pads of rats fed highMCT diets are smaller compared with those in rats fed longchain triacylglycerides. Although the mechanism is not known, it is attributed to higher oxidation and enhancement of thermogenesis $(22,33)$. Despite the lower food intake by the HF-MCT group, the total fat consumed per day was increased in this group $(2.7 \mathrm{~g} / \mathrm{d})$ compared with the LF-MCT and control groups $(0.6 \mathrm{~g} / \mathrm{d}$; see Table 2$)$.

In the present study, MCT at LF and MF levels elevated PL activity whereas MCT at HF levels did not affect PL activity. No previous study reports induction of PL activity by low levels of MCT, as this was not examined. High MCT $(67 \%$ of energy) did not induce PL activity in our study in contrast to high long-chain fatty acids ( $67 \%$ of energy), which did induce PL activity in our previous study (19). However, increasing long chain fatty acids to $75 \%$ of energy in the diet diminishes
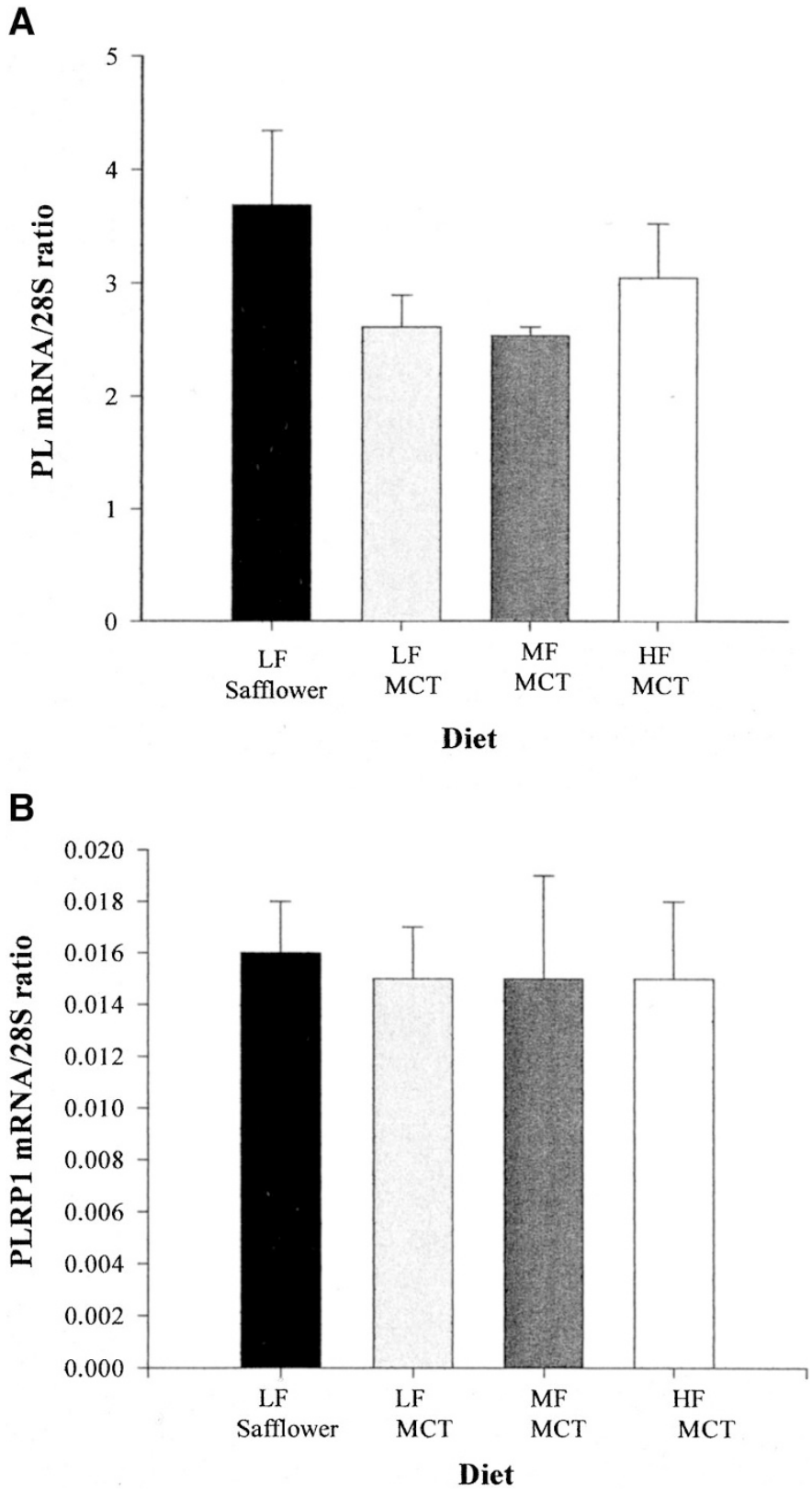

Figure 2. (A) PL mRNA/28S RNA ratio. (B) PLRP1 mRNA/28S ratio. Weanling Sprague Dawley rats were fed for $7 \mathrm{~d}$ diets with LF- $(11 \%$ of energy), MF- (40\% of energy), or HF-MCT (67\% of energy) or low-fat safflower (control) diets. Results are expressed as mean \pm SE $(n=5$ per group). There was no significant difference among the groups, for either PL mRNA or PLRP1 mRNA.

the PL activity compared with that seen with $67 \%$ long-chain fatty acids (19). Further, a dietary ketone precursor, butanediol, also exhibited a biphasic effect on PL activity with increased PL activity by $7.5 \%$ and $14 \%$ butanediol but no change in PL activity by $28 \%$ (34). The biphasic response to MCT is congruent with the biphasic response to LCT and dietary ketones. Why such a biphasic response by PL occurs is unknown, but such a response may result from biphasic effects on the hormonal or metabolic mediators of this dietary regulation. Alternatively, another explanation of this biphasic response may be that MCT have a higher formation rate of emulsion particles and thereby enhanced hydrolysis by PL (35). The released 


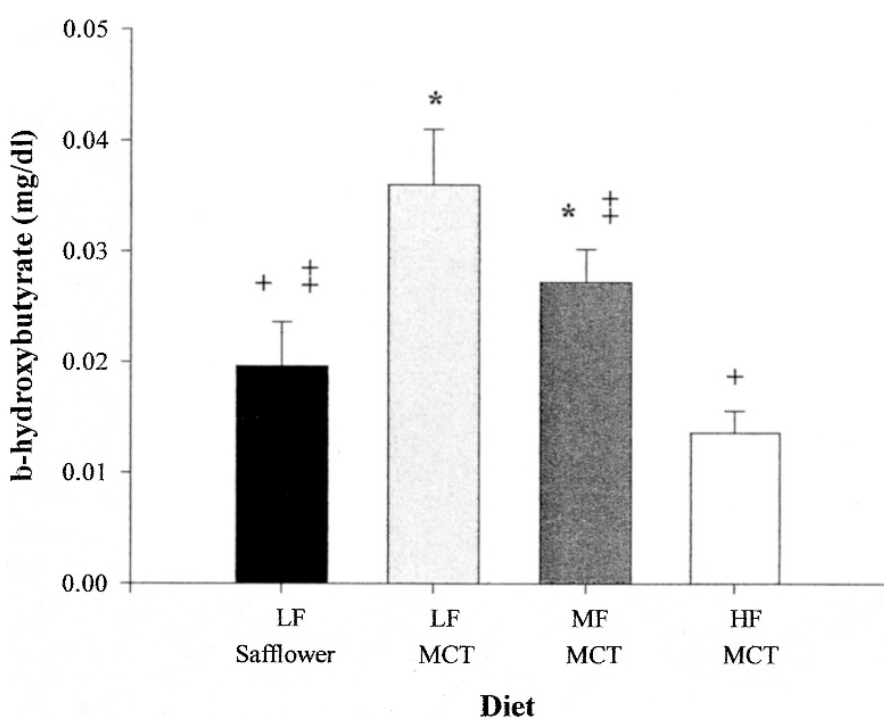

Figure 3. Plasma $\beta$-hydroxybutyrate $(\mathrm{mg} / \mathrm{dL})$. Weanling Sprague Dawley rats were fed for $7 \mathrm{~d}$ diets with LF- (11\% of energy), MF- (40\% of energy), or HF-MCT (67\% of energy) or low-fat safflower (control) diets. Results are expressed as mean $\pm \mathrm{SE}\left(n=5\right.$ per group). ${ }^{*} \dagger$ Values not sharing a superscript differed significantly $(p<0.02)$ by ANOVA and LSD.

medium-chain fatty acids (MCFA) may exert less allosteric inhibition on PL, and medium-chain 2-monoglycerides may isomerize more rapidly than those of long-chain length, thereby facilitating rapid hydrolysis (33). Such rapid hydrolysis might affect the regulation of PL through effects on either the release of secretin or gastric inhibitory polypeptide, proposed mediators of the dietary regulation of $\mathrm{PL}(36,37)$, or the generation of ketones, another proposed mediator (38). MCT are known to be oxidized more readily than LCT and may generate greater amounts of ketone at lower levels. The generation of ketones from MCT could be further enhanced by a more rapid hydrolysis and uptake of MCFA. Plasma concentration of $\beta$-hydroxybutyrate was also significantly higher in rats fed LF-MCT compared with rats fed LF-safflower in this study, whereas $\beta$-hydroxybutyrate plasma concentration of rats fed MF-MCT was intermediate. This parallel pattern of $\beta$-hydroxybutyrate plasma concentration and PL activity supports the proposed role of ketones in mediating the dietary regulation of PL and may explain the more robust response of PL to low amounts of MCT. In contrast, lipolysis of emulsified LCT may be inhibited by the soaps formed during the reaction and by their poor diffusion to the aqueous phase (39), which might result in less stimulation of the proposed mediators at lower dietary levels.

The lack of effect of high levels of MCT on PL has been reported by others. Saraux et al. (18) found that MCT did not increase PL content to the same extent as other fats, although they used only one high level of MCT in the diet $(45 \%$ by weight). Furthermore, PL activity in their study was $67.3 \mathrm{U} / \mathrm{mg}$ of protein, which is very similar to the level we found at high dietary fat levels (31.6\% by weight) of MCT $(57.7 \mathrm{U} / \mathrm{mg}$ protein) in our study. Deschodt-Lanckman et al. (17) demonstrated a similar "poor induction" of PL in adult rats by $50 \%$ (by weight) of tricapric oil in the diet, but PL activity reached the same levels as we found in high levels of MCT diet (50
U/mg protein). Sabb et al. (19) demonstrated that increased dietary fat does not influence PL activity in a linear way; rather, PL activity response occurs past a threshold level of dietary fat and decreases beyond maximal levels (67\% for corn oil). This decrease in PL activity occurs at a lower threshold when MCT is used as a fat source in the diet as described in this study.

The mechanism whereby MCT regulates PL appears to be translational or posttranslational, as PL and PLRP1 mRNA levels do not parallel the changes in PL activity. Our previous study (16) suggests that the degree of saturation of dietary fat regulates PL translationally or posttranslationally, because long-chain saturated and polyunsaturated triglycerides induced nonparallel changes in PL mRNA level and activity. The results of the present study also suggest that the amount of MCT also regulates PL translationally or posttranslationally because of the nonparallel changes in activity and mRNA levels. Further studies are needed to examine the effects of MCT on the synthesis, secretion, and degradation of PL.

Some studies emphasize the importance and advantages of using MCT in infant formulas: 1) higher rate of absorption, more rapid transport, and more efficient oxidation compared with LCT; 2) improved LCT absorption when combined with MCT; and 3) improved nitrogen and calcium absorption (32, 40-43). However, the use of MCT in formulas of premature infants and newborns has been questioned by others (44). High levels of MCT in the diet are not recommended because they may elevate the levels of circulating dicarboxylic acids and ketones (40). In previous studies, MCT-containing formulas were absorbed at a similar rate to LCT-containing formula when $50 \%$ of energy was MCT or LCT. Furthermore, the activity of gastric lipase is higher in formulas containing LCT compared with MCT $(43,45)$.

The present study demonstrates that MCT in the diet at low or moderate levels (11\% and $40 \%$ of energy) elevates PL activity significantly in the weanling rat. This regulation of $\mathrm{PL}$ by MCT could be important for optimizing dietary triglyceride absorption by adjusting the MCT/LCT ratio to stimulate maximal PL activity and its "feed forward" coordination of fat digestion and avoid adverse effects of high levels of MCT in the diet.

The results of the present study strengthen the concern regarding the use of high levels of MCT in infant's formula. Considering that LCT induces higher gastric lipase activity and that our results show higher levels of PL activity at low and moderate levels of $\mathrm{MCT}$, it seems that lowering the ratio of MCT/LCT may be advisable.

\section{REFERENCES}

1. Carriere F, Barrowman JA, Verger R, Laugier R 1993 Secretion and contribution to lipolysis of gastric and pancreatic lowpass during a test meal in humans. Gastroenterology 105:876-888

2. Payne RM, Sims HF, Jennens ML, Lowe ME 1994 Rat pancreatic lipase and two related proteins: enzymatic properties and mRNA expression during development. Am J Physiol 266:G914-G921

3. Brannon PM 1990 Adaptation of the exocrine pancreas to diet. Ann Rev Nutr 10:85-105

4. Dagorn JC 1986 Mechanism of pancreas adaptation to diet. Biochimie 68:329-331

5. Gidez LI 1973 Effect of dietary fat on pancreatic lipase levels in the rat. J Lipid Res $14: 169-177$ 
6. Lowe ME, Rosenblum JL, Strauss AW 1989 Cloning and characterization of human pancreatic lipase cDNA. J Biol Chem 264:20042-20048

7. Wicker-Planquart C, Puigserver A 1992 Primary structure of rat pancreatic lipase mRNA. FEBS Lett 296:61-66

8. Giller T, Buchwald P, Blum-Kaelin D, Hunziker W 1992 Two novel human pancreatic lipase related proteins, hPLRP1 and hPLRP2. J Biol Chem 267:16509-16516

9. Crenon I, Jayne S, Kerfelec B, Hermoso J, Pignol D, Chapus C 1998 Pancreatic lipase-related protein type 1: a double mutation restores a significant lipase activity. Biochem Biophys Res Commun 246:513-517

10. Lowe ME 1997 Molecular mechanisms of rat and human pancreatic triglyceride lipase. J Nutr 127:549-557

11. Andersson L, Carriere F, Lowe ME, Nilson A, Verger R 1996 Pancreatic lipaserelated protein 2 but not classical pancreatic lipase hydrolyzes galactolipids. Biochim Biophys Acta 1302:236-240

12. Spannagel AW, Nakano I, Tawil T, Chey WY, Liddle RA, Green GM 1996 Adaptation to fat markedly increases pancreatic secretory response to intraduodenal fat in rats. Am J Physiol 270:G128-G135

13. Schwizer W, Asal K, Kreiss C, Mettraux C, Borovicka J, Remy R, Guezelhan C, Hartman D, Fried M 1997 Role of lipase in the regulation of upper gastrointestinal function in humans. Am J Physiol 273:G612-G620

14. Wicker C, Puigserver A 1989 Changes in mRNA levels of rat pancreatic lipase in the early days of consumption of a high lipid diet. Eur J Biochem 180:563-567

15. Wicker C, Puigserver A 1990 Expression of rat pancreatic lipase gene is modulated by a lipid-rich diet at a transcriptional level. Biochem Biophy Res Commun 166:358 364

16. Ricketts J, Brannon PM 1994 Amount and type of dietary fat regulate pancreatic lipase gene expression in rats. J Nutr 124:1166-1171

17. Deschodt-Lanckman M, Robberecht P, Camus J, Christophe J 1971 Short- term adaptation of pancreatic lipase hydrolases to nutritional and physiological stimuli in adult rats. Biochemie 53:789-796

18. Saraux B, Girard-Globa A, Ouagued M, Vacher D 1982 Response of the exocrine pancreas to quantitative and qualitative variations in dietary lipids. Am J Physiol 243:G10-G15

19. Sabb JE, Godfrey PM, Brannon PM 1986 Adaptive response of rat pancreatic lipase to dietary fat: effects of amount and type of fat. J Nutr 116:892-899

20. Hamosh M 1995 Lipid metabolism in pediatric nutrition. Pediatric Clin N Am 42:839-859

21. Bach AC, Igenbleek Y, Frey A 1996 The usefulness of dietary medium chain triglycerides in body weight control: fact or fantasy? J Lipid Res 37:708-726

22. Bach AC, Babayan VK 1982 Medium chain triglycerides: an update. Am J Clin Nutr $36: 950-962$

23. Schneeman BO, Gallaher D 1980 Changes in small intestinal digestive enzyme activity and bile acids with dietary cellulose in rats. J Nutr 110:584-590

24. Lowry OH, Rosenbaugh NJ, Farr AL, Randell RJ 1951 Protein measurement with the folin phenol reagent. J Biol Chem 193:265-275

25. Williamson DH, Mellanby J, Krebs HA 1962 Enzymatic determination of D (-) $\beta$-hydroxybutyric acid and acetoacetic acid in blood. Biochem J 82:90-96

26. Chomczynski P, Sacchi N 1987 Single step method of isolation by acid guanidinium thiocyanate-phenol-chloroform extraction. Anal Biochem 162:156-159
27. Steinhilber W, Poensgen J, Rausch U, Kern HF, Scheele GA 1988 Translational control of anionic trypsinogen and amylase synthesis in rat pancreas in response to caerulein stimulation. Proc Natl Acad Sci U S A 85:6597-6601

28. Wishart MJ, Andrews PC, Nichols R, Blevis GT, Logsdon CD, Williams JA 1993 Identification and cloning of the GP-3 from rat pancreatic acinar zymogen granules as a glycosylated membrane-associated lipase. J Biol Chem 268:10303-10311

29. Grusby MJ, Nabavi N, Wong H, Dick RF, Bluestone JA, Schotz MC, Glimcher LH 1990 Cloning of an interleukin-4 inducible gene from cytotoxic T lymphocytes and its identification as a lipase. Cell 60:451-459

30. Tsai A, Cowan MR, Johnson DG, Brannon PM 1994 Regulation of pancreatic amylase and lipase gene expression by diet and insulin in diabetic rats. Am J Physiol 267:G575-583

31. Steel RGD, Torrie JH 1960 Principles and Procedures of Statistics. McGraw-Hill, New York

32. Tantibhedhyangkul P, Hashim SA 1975 Medium-chain triglyceride feeding in premature infants: effect on fat and nitrogen absorption. Pediatrics 55:359-365

33. Odle J 1997 New insights into the utilization of medium chain triglycerides by the neonate; observations from a piglet model. J Nutr 127:1061-1067

34. Shenoy S, Yager BK, Brannon PM 1998 Role of ketones in the regulation of pancreatic lipase by dietary fat. FASEB J 12:A514

35. Armand M, Borel P, Ythier P, Dutot G, Melin C, Senft M, Lafont H, Lairon D 1992 Effects of droplet size, triacylglycerol composition, and calcium on the hydrolysis of complex emulsions by pancreatic lipase: an in vitro study. J Nutr Biochem 3:333-341

36. Rausch G, Rudiger K, Vasilouds P, Kern HF, Scheele G 1986 Lipase synthesis in the rat pancreas is regulated by secretin. Pancreas 6:522-528

37. Duan R, Erlanson-Albertsson C 1992 Gastric inhibitory polypeptide stimulates pancreatic lipase and colipase synthesis in rats. Am J Physiol 262:G779-G784

38. Bazin R, Lavau M 1979 Diet composition and insulin effects on amylase to lipase ratio in pancreas of diabetic rats. Digestion 19:386-391

39. Benzonana G, Desnuelle P 1968 Action of some effectors on the hydrolysis of long-chain triglycerides by pancreatic lipase. Biochim Biophys Acta 164:47-58

40. Lien EL 1994 The role of fatty acid composition and positional distribution in fat absorption in infants. J Pediatr 125:s62-s68

41. Hashim SA, Tantibhedyangkul P 1987 Medium chain triglyceride in early life: effects on growth on growth of adipose tissue. Lipids 22:429-434

42. Tantibhedhyangkul P, Hashim SA 1978 Medium-chain triglyceride feeding in premature infants: effect on calcium and magnesium absorption. Pediatrics 61:537-545

43. Hamosh M, Mehta NR, Fink CS, Coleman J, Hamosh P 1991 Fat absorption in premature infants: medium chain triglycerides and long chain triglycerides are absorbed from formula at similar rates. J Pediatr Gastroenterol Nutr 28:143-149

44. Sulkers HJ, vGoudoever JB, Leunisse C, Wattimena JLD, Sauer PJJ 1992 Comparison of two preterm formulas with or without addition of medium-chain triglycerides (MCTs). I: Effect on nitrogen and fat balance and body composition changes. J Pediatr Gastroenterol Nutr 15:34-41

45. Hamosh M, Bitman J, Liao TH, Mehta NR, Buczek RJ, Wood DL, Grylack LJ, Hamosh P 1989 Gastric lipolysis and fat absorption in premature infants: effect of medium chain triglyceride or long chain triglyceride-containing formulas. Pediatrics 83:86-92 